\title{
Examining the mechanical properties and superplastic behaviour in an Al-Mg-Sc alloy after processing by HPT
}

\author{
P.H. R. Pereira ${ }^{1,2 \dagger}$, Y. Huang ${ }^{1}$, T. G. Langdon ${ }^{1,3}$ \\ †phrp1d13@soton.ac.uk \\ ${ }^{1}$ Materials Research Group, Faculty of Engineering and the Environment, University of Southampton, \\ Southampton SO171BJ, U. K. \\ ${ }^{2}$ CAPES Foundation, Ministry of Education of Brazil, Brasília — DF 70040—020, Brazil \\ ${ }^{3}$ Departments of Aerospace \& Mechanical Engineering and Materials Science, University of Southern California, \\ Los Angeles, CA 90089-1453, U.S. A.
}

Experiments were conducted using the solution treated Al-3\% Mg- $0.2 \%$ Sc alloy in order to examine the mechanical properties and superplastic behaviour after processing by high-pressure torsion. Hardness values of $\sim 200 \mathrm{Hv}$ were detected in the edge of the samples after 10 turns of HPT, although the microhardness distribution was inhomogeneous along the diameter of the discs. Excellent superplastic properties were achieved in this Al alloy after HPT processing and further tensile testing at temperatures over the range from 523 to $673 \mathrm{~K}$, demonstrating good agreement with the theoretical model for grain boundary sliding. High strain rate superplasticity was consistently observed at temperatures from 573 to $623 \mathrm{~K}$, with elongations to failure up to $\sim 800 \%$ at $573 \mathrm{~K}$ and at a strain rate of $1.4 \times 10^{-2} \mathrm{~s}^{-1}$. Further analysis of the experimental data revealed that the stress exponent at the testing conditions displaying elongations $>400 \%$ was $\sim 2$ thereby demonstrating good agreement with the theoretical model for grain boundary sliding. The calculated activation energies lie in the range from $\sim 98$ to $\sim 118 \mathrm{~kJ} \mathrm{~mol}^{-1}$ and are similar to the value obtained for the same alloy after ECAP which is within the range for grain boundary diffusion in pure $\mathrm{Al}$ and interdiffusion in $\mathrm{Al}-\mathrm{Mg}$ alloys.

Keywords: aluminium alloys, grain boundary sliding, high-pressure torsion, severe plastic deformation, superplasticity

\section{Исследование механических свойств и сверхпластического поведения сплава Al-Mg-Sc после обработки КВД}

Проведены эксперименты с использованием сплава Al-3\% Mg-0.2\% Sc, подвергнутого термообработке на твердый раствор, направленные на исследование механических свойств и сверхпластического поведения после обработки путем кручения под высоким давлением (КВД). На краях образцов после 10 оборотов КВД обнаружены значения твердости около $200 \mathrm{Hv}$, хотя распределение микротвердости по диаметру дисков было неоднородно. После деформации методом КВД при испытаниях растяжением в температурном интервале от 523 до 673 К достигнуты исключительно высокие сверхпластические свойства данного сплава. При температурах от 573 до 623 К последовательно наблюдалась высокоскоростная сверхпластичность с удлинениями до разрушения вплоть до 800 \% при 573 К и скорости деформации $1.4 \times 10^{-2} \mathrm{c}^{-1}$. Дальнейший анализ экспериментальных данных показал, что показатель при напряжении в условиях испытаний, приводящих к удлинениям более 400\%, составлял примерно 2, таким образом демонстрируя хорошее согласие с теоретической моделью зернограничного проскальзывания. Рассчитанные энергии активации лежат в интервале от 98 до 118 кДж моль-1 и близки к значению, полученному для того же сплава после РКУП, которое лежит в интервале значений для зернограничной диффузии в чистом $\mathrm{Al}$ и взаимной диффузии в сплавах $\mathrm{Al-Mg}$.

Ключевые слова: алюминиевые сплавы, зернограничное проскальзывание, кручение под высоким давлением, интенсивная пластичсекая деформация, сверхпластичность

\section{Introduction}

The processing of metallic materials through severe plastic deformation (SPD) methods has been extensively performed in order to produce bulk solids having exceptionally small grain sizes $[1,2]$. As a consequence of the intense straining and grain refinement, these materials generally exhibit increased mechanical strength at low temperatures, as well 
as higher diffusion rates so that, if the grain boundaries are reasonably stable at elevated temperatures, it is possible to achieve excellent superplastic properties. Among the various SPD techniques [3], notable attention is given to EqualChannel Angular Pressing (ECAP) [4] and High Pressure Torsion (HPT) [5] which is more effective than ECAP regarding the fabrication of ultrafine-grained bulk solids with grain sizes in the nanometre range $(<0.1 \mu \mathrm{m})$.

Considering that the strain rate in superplasticity is inversely proportional to the square of the grain size [6], several studies have been conducted with the objective of producing nanostructured metals for use in superplastic forming operations at faster production rates [7]. Extraordinary superplastic properties have been reported in a large number of aluminium alloys after severe plastic deformation $[8,9]$, especially in the case of Al-Mg-Sc alloys [10,11]. The presence of $\mathrm{Mg}$ in solid solution in these alloys delays their recovery kinetics and leads to further grain refinement during SPD processing by comparison with pure aluminium [12]. Furthermore, the $\mathrm{Al}_{3} \mathrm{Sc}$ precipitates significantly improve the recrystallization resistance in $\mathrm{Al}-\mathrm{Mg}$-Sc alloys and thus retain fine grain sizes at high temperatures suitable for superplastic forming [13].

There are numerous reports in the literature dealing with the evaluation of the superplastic properties of Al-Mg based alloys with Sc additions after processing by ECAP [10,11,14-16], friction stir processing [17], cold-rolling [18] and free forging [19]. Conversely very few and only isolated studies were performed using High-Pressure Torsion [20-22] and more data are needed to fully assess and understand the superplastic behaviour of this alloy after HPT processing.

The present work aims to systematically evaluate the mechanical properties and superplastic behaviour of the Al$3 \% \mathrm{Mg}-0.2 \% \mathrm{Sc}$ alloy and provide new information regarding the range of temperatures and strain rates in which this alloy exhibits superplastic flow after processing by HPT.

\section{Experimental material and procedures}

The Al-3\% Mg- $0.2 \%$ Sc (\% in weight) alloy was used in the current investigations. This material was supplied by China Rare Metal Material Corporation (JiangXi Province,China) in the form of forged rods having a diameter of $10 \mathrm{~mm}$ and a length of $130 \mathrm{~mm}$. These rods were solutionised at $880 \mathrm{~K} \pm 2$ $\mathrm{K}$ for 1 hour and quenched in water. Optical micrographs of the samples after solution treatment revealed the presence of an equiaxed and homogeneous grain structure with a grain size of $\sim 300 \mu \mathrm{m}$. After heat treatment, the Al-3Mg-0.2Sc rods were cut into discs with a thickness of $\sim 1 \mathrm{~mm}$ and $10 \mathrm{~mm}$ in diameter. Discs were ground using abrasive papers until a thickness of $\sim 0.82 \mathrm{~mm}$ and then processed through 10 turns of HPT using anvils with a quasi-constrained configuration [23] at an initial temperature of $\sim 300 \mathrm{~K}$ using a rotation rate of $1 \mathrm{rpm}$ and a nominal pressure of $6.0 \mathrm{GPa}$. The temperature rise during HPT processing was estimated using the equations obtained in a recent report [24] and it was verified that after 10 turns the $\mathrm{Al}-3 \mathrm{Mg}-0.2 \mathrm{Sc}$ discs achieve a temperature of $\sim 333 \mathrm{~K}$.

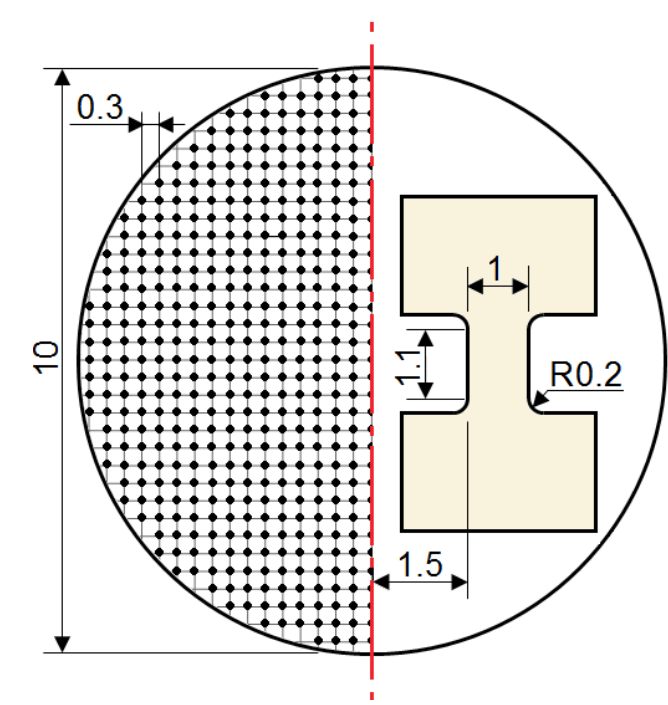

Fig. 1. Illustration of an HPT disc displaying the geometry of the tensile specimen and $(\cdot)$ the position where the microhardness distribution along the disc surface was recorded.

Following HPT processing, discs were mounted, ground and polished to a mirror like quality and the microhardness distribution in their mid-sections parallel to the upper and lower surfaces was evaluated at the positions illustrated in Fig. 1. The values of the Vickers microhardness were recorded using an FM300 microhardness tester equipped with a Vickers indenter under a load of 200 gf and a dwell time of $15 \mathrm{~s}$. Hardness measurements were taken over the entire disc surfaces following a rectilinear grid pattern with indentations separated by a distance of $0.3 \mathrm{~mm}$, using the same procedure described in an earlier study [25].

After HPT processing, the discs became curved as a consequence of the elastic distortion of the anvils [26]. Accordingly, the upper and lower surfaces of the discs were ground using abrasive papers to a thickness of $\sim 0.60 \mathrm{~mm}$ in order to obtain a uniform thickness and remove the surface irregularities of the samples. Thereafter, tensile specimens were cut from the HPT processed discs, as schematically illustrated in Fig. 1. Two specimens were cut from each disc using wire electrical discharge machining. Each tensile specimen was pulled to failure using a Zwick Z030 testing machine equipped with furnace and operating at a constant rate of cross-head displacement. The Al-3Mg-0.2Sc alloy was tested in the temperature range of $523-673 \mathrm{~K}$ and at initial strain rates, $\dot{\varepsilon}$, from $4.5 \times 10^{-4}$ to $1.4 \times 10^{0} \mathrm{~s}^{-1}$. The samples were held at the testing temperature, $\mathrm{T}$, for $\sim 15$ minutes prior to the load application in order to reach thermal equilibrium and during tensile testing the testing temperature was held constant to within $\pm 2 \mathrm{~K}$. The gauge length and the width of each specimen immediately after machining were measured through images taken using an Olympus BX51 microscope and a digital calliper was used to measure the initial thickness of the specimens. A Wild M420 stereoscope was used to obtain images of the samples after tensile testing and to measure the final length in the gauge section of the $\mathrm{Al}-3 \mathrm{Mg}-0.2 \mathrm{Sc}$ samples.

Following tensile testing, both the fracture surface and the topography in the gauge section of the Al-3Mg-0.2Sc specimens were observed using a JSM-6500F scanning 
electron microscope with a field emission electron source, operating at $15 \mathrm{kV}$. The images obtained by scanning electron microscopy (SEM) were used to measure the mean linear intercept grain size, $\overline{\mathrm{L}}$, and calculate the spatial grain size, $\mathrm{d}$, using the expression $\mathrm{d}=1.74 \overline{\mathrm{L}}$ [27].

\section{Experimental results}

Prior to HPT processing, the Al-Mg-Sc discs had a uniform thickness of $\sim 0.82 \mathrm{~mm}$ and this was reduced to $\sim 0.70 \mathrm{~mm}$ at the centre and $\sim 0.63 \mathrm{~mm}$ at the edge of the discs processed by HPT through 10 turns. In order to evaluate in detail the microhardness distribution in the middle-section position of $\mathrm{Al}-\mathrm{Mg}$-Sc discs processed through 10 turns of HPT processing, hardness measurements were taken over the entire disc surface, following a rectilinear grid pattern with a separation of $0.3 \mathrm{~mm}$ between each point. These individual hardness values were then used to construct a colour-coded contour map delineating the variations of the Vickers microhardness across the surface of the disc, as depicted in Fig. 2.

Hardness measurements were also taken in the solution treated Al-Mg-Sc alloy before HPT processing and they revealed the discs had a homogeneous hardness distribution with microhardness values of $\sim 60 \mathrm{Hv}$. It is apparent from Fig. 2 there is a significant increase in the hardness along the diameter of the disc after 10 turns of HPT processing. The Vickers microhardness distribution is approximately axisymmetric and the hardness increases with increasing distance from the centre of disc. After 10 turns of HPT processing, hardness values smaller than $\sim 150 \mathrm{Hv}$ were found in the central region of the discs for radial positions, $r$, smaller than $\sim 1 \mathrm{~mm}$. Furthermore, for $\mathrm{r}>1.5 \mathrm{~mm}$ which corresponds to the position where the tensile specimens were machined, it is noted that the Vickers microhardness varies from $~ 190-210$ $\mathrm{Hv}$ such that a fairly homogeneous hardness distribution is attained along the gauge section of the tensile specimens of

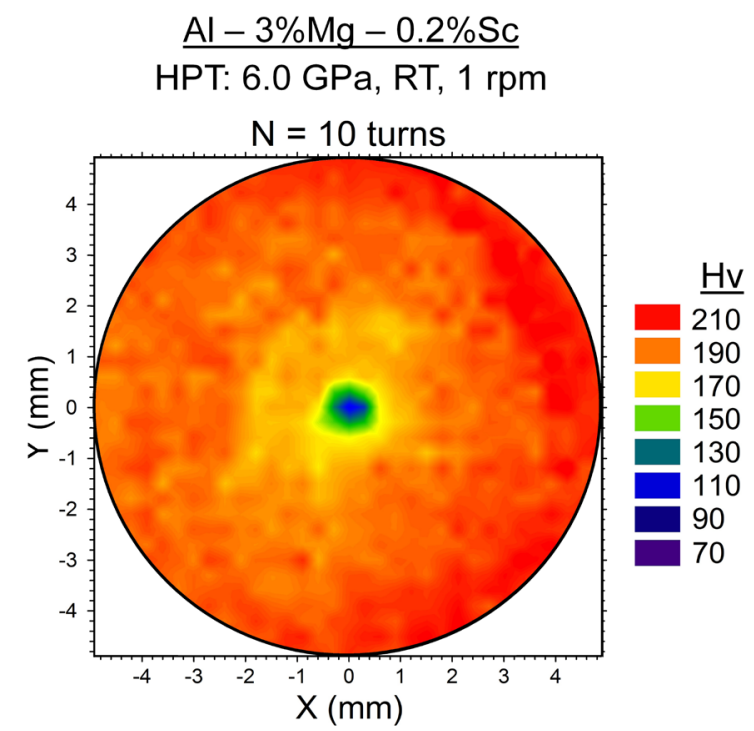

Fig. 2. Colour-coded contour map showing the distribution of the Vickers microhardness over the surfaces of an Al-3Mg-0.2Sc disc processed by HPT through 10 turns.

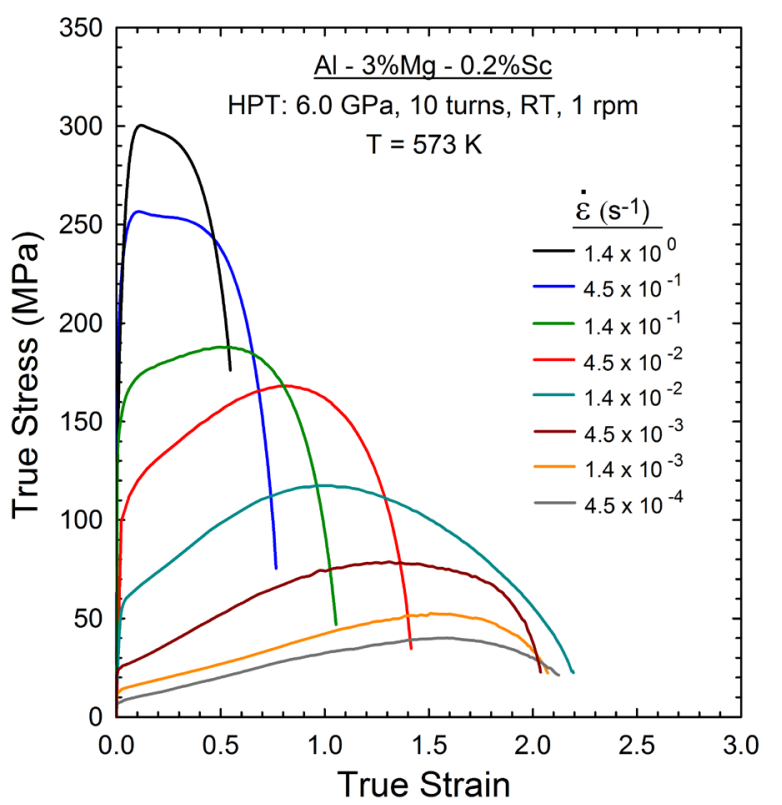

Fig. 3. True stress vs true strain for $\mathrm{Al}-3 \mathrm{Mg}-0.2 \mathrm{Sc}$ samples tested at $573 \mathrm{~K}$ after 10 turns of HPT processing.

the Al-3Mg-0.2Sc alloy.

Figure 3 shows plots of the true stress vs true strain for the tensile specimens which were processed through 10 turns of HPT and pulled to failure at $573 \mathrm{~K}$ using initial strain rates from $4.5 \times 10^{-4}$ to $1.4 \times 10^{0} \mathrm{~s}^{-1}$. Inspection of the curves depicted in Fig. 3 reveals that at this testing temperature the specimens exhibited extremely high values of true strain prior to failure in tension, particularly in the case of the samples tested using initial strain rates within the range from $4.5 \times 10^{-4}$ to $1.4 \times 10^{-}$ ${ }^{2} \mathrm{~s}^{-1}$ which attained true strains higher than 2 prior to failure. It is also noted from these curves that significant work hardening was observed in the samples tested from $4.5 \times 10^{-4}$ to $1.4 \times 10^{-2} \mathrm{~s}^{-1}$ which achieved their maximum values of true stress for true strains higher than $\sim 1$.

The very high elongations attained in the Al-3Mg-0.2Sc samples processed by HPT are shown in Fig. 4 where the shapes of the specimens are depicted after tensile testing at $573 \mathrm{~K}$ using strain rates from $4.5 \times 10^{-4}$ to $1.4 \times 10^{-2} \mathrm{~s}^{-1}$. It is verified from Fig. 4 there is an absence of necking and elongations to failure higher than $400 \%$ in the specimens pulled to failure at these testing conditions. Furthermore, an elongation to failure of $\sim 800 \%$ was achieved at $\dot{\varepsilon}=1.4 \times 10^{-2} \mathrm{~s}^{-1}$ indicating the occurrence of high strain rate superplasticity in the Al-3Mg-0.2Sc alloy solution treated and further processed by 10 turns of HPT.

The elongations to failure obtained after performing tensile testing over a wide range of temperatures and strain rates are depicted in Fig. 5 with the Al-Mg-Sc samples processed by 10 turns of HPT.

Figure 5 shows that elongations to failure higher than $400 \%$ were obtained after tensile testing from 523 to $623 \mathrm{~K}$ at strain rates from $4.5 \times 10^{-4}$ to $1.4 \times 10^{-2} \mathrm{~s}^{-1}$. By contrast, it is noted that relatively low elongations were attained at $673 \mathrm{~K}$, particularly using $\dot{\varepsilon}>1.4 \times 10^{-3} \mathrm{~s}^{-1}$. In addition, it is worth noting that the highest elongation obtained in the current investigation was $\sim 850 \%$ and it was obtained at the testing temperature of $523 \mathrm{~K}$ and at the initial strain rate of $4.5 \times 10^{-3} \mathrm{~s}^{-1}$. 


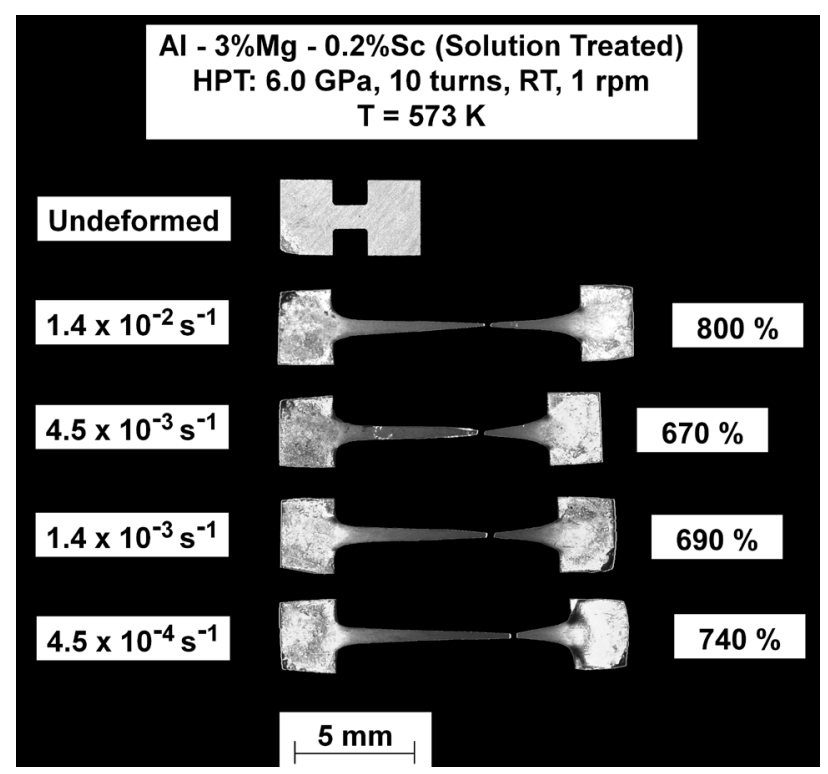

Fig. 4. Shapes of the Al-3Mg- $0.2 \mathrm{Sc}$ specimens tested at $573 \mathrm{~K}$ after 10 turns of HPT processing.

It is apparent from Fig. 5 that the $\mathrm{Al}-3 \mathrm{Mg}-0.2 \mathrm{Sc}$ specimens processed by high-pressure torsion display higher ductility in the temperature range from $\sim 523-573 \mathrm{~K}$ and beyond these temperatures there is a consistent trend of decrease in the elongation to failure with increasing temperatures at a given strain rate.

The fracture surface and the surface topography along the gauge section and next to the head of the Al-3Mg-0.2Sc alloy processed by HPT and further subjected to tensile testing at $573 \mathrm{~K}$ and at $\dot{\varepsilon}=1.4 \times 10^{-2} \mathrm{~s}^{-1}$ were examined through SEM images as displayed in Fig. 6. It is noted from the appearance of the fracture surface shown in Fig. 6a that the failure of the $\mathrm{Al}-3 \mathrm{Mg}-0.2 \mathrm{Sc}$ specimen during tensile testing

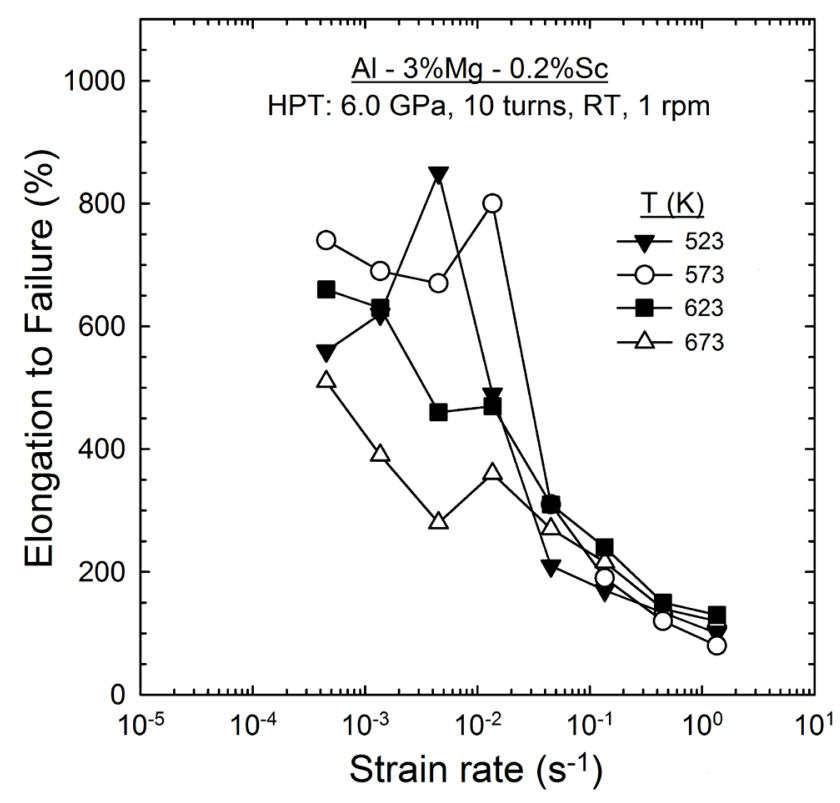

Fig. 5. Elongation to failure vs strain rate for $\mathrm{Al}-3 \mathrm{Mg}-0.2 \mathrm{Sc}$ samples tested from 523 to $673 \mathrm{~K}$ after 10 turns of HPT.

occurred by a ductile intergranular fracture. During plastic deformation the grains stand out in relief on the surface of tensile specimens. This phenomenon is clearly observed in Fig. $6 b$ and $c$ which provide valuable information concerning the distribution and morphology of the grains in the deformed Al-Mg-Sc specimens tested in tension at $573 \mathrm{~K}$ and at $\dot{\varepsilon}=1.4 \times 10^{-2} \mathrm{~s}^{-1}$. It is readily apparent from Fig 6 b the occurrence of grain boundary sliding (GBS) on the tensile specimen which attained an elongation to failure of $\sim 800 \%$. Additionally, it is noteworthy that the grains in the gauge section of the Al-3Mg-0.2Sc specimen are mainly equiaxed and ultrafine even after extensive plastic deformation providing mi-

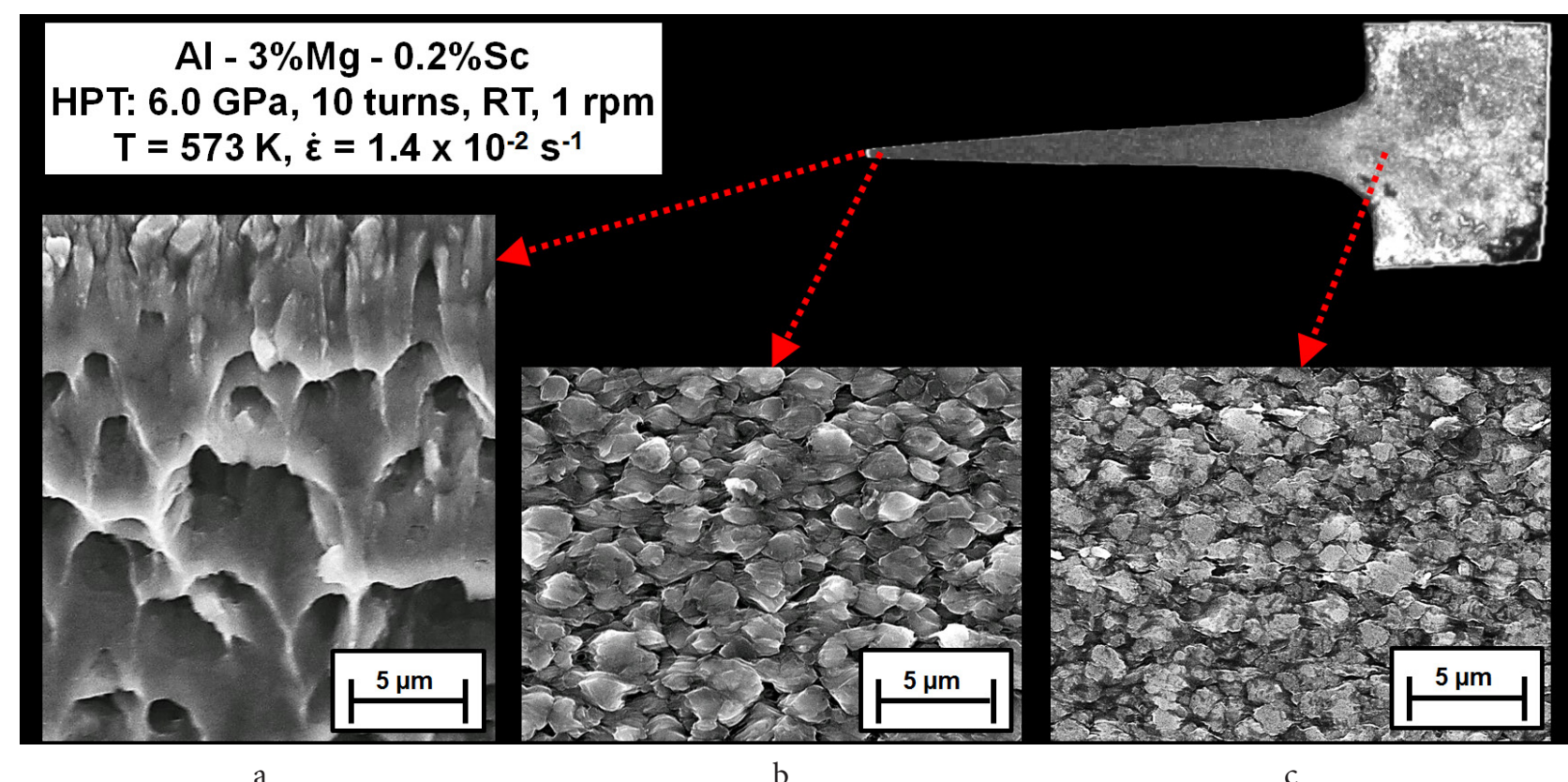

Fig. 6. SEM images of the tensile specimens of the Al-3Mg-0.2Sc subjected to 10 turns of HPT processing and further pulled to failure at $573 \mathrm{~K}$ and at $\dot{\varepsilon}=1.4 \times 10^{-2} \mathrm{~s}^{-1}$. The images depict (a) the fracture surface as well as the surface topography of the specimens (b) in the gauge section near the fracture tip and (c) next to the head of the work-piece. 
croestrutural evidence of the high strain rate superplasticity with grain boundary sliding as the dominant deformation mechanism in the Al-3Mg-0.2Sc alloy after processing by HPT. Moreover, Fig. $6 c$ shows that the grains in the vicinity of the head of the specimen are also equiaxed with average grain sizes very similar to the grains next to the fracture tip.

The same procedure used to examine the surface topography in the gauge section of the $\mathrm{Al}-3 \mathrm{Mg}-0.2 \mathrm{Sc}$ specimens processed by HPT and pulled to failure at $573 \mathrm{~K}$ and at $\dot{\varepsilon}=1.4 \times 10^{-2} \mathrm{~s}^{-1}$ was used to study the distribution and average size of grains of the same material subjected to tensile testing at the other testing conditions employed in the current investigation. Thereafter, the linear intercept method was used to measure the mean linear intercept grain size and thus calculate the spatial grain size, $d$.

Figure 7 shows the evolution of the spatial grain size, $d$, with the total heating time of the $\mathrm{Al}-3 \mathrm{Mg}-0.2 \mathrm{Sc}$ specimens measured using SEM images of the work-pieces processed by 10 turns of HPT and further tested at temperatures from 523 to $673 \mathrm{~K}$. It is verified from the plots depicted in Fig. 7, that there is some grain growth during the time required to attain thermal equilibrium before tensile testing, although the grains remain very small even at the highest temperature used in the current study. The spatial grain sizes were measured as $\sim 0.4, \sim 1.0, \sim 1.6$ and $\sim 3.1 \mu \mathrm{m}$ after heating for $\sim 15$ minutes at $523,573,623$ and $673 \mathrm{~K}$, respectively, and they exhibit good agreement with the mean linear intercept grain size reported for the same Al-Mg-Sc alloy processed by ECAP and held at temperatures from 573 to $723 \mathrm{~K}$ for $\sim 10$ minutes [10].

After tensile testing at the selected temperatures the $\mathrm{Al}-3 \mathrm{Mg}-0.2 \mathrm{Sc}$ samples also displayed some grain growth by comparison with the samples just before tensile testing. As depicted in Fig. 7, the calculated grain size in the gauge section of the specimens tested at $523 \mathrm{~K}$ is smaller than $\sim 2.3 \mu \mathrm{m}$ even after the testing performed using $\dot{\varepsilon}=4.5 \times 10^{-4} \mathrm{~s}^{-1}$ which corresponds to a total heating time higher than $10^{4} \mathrm{~s}$. Nevertheless, it is also shown in Fig. 7 that the specimens tested at

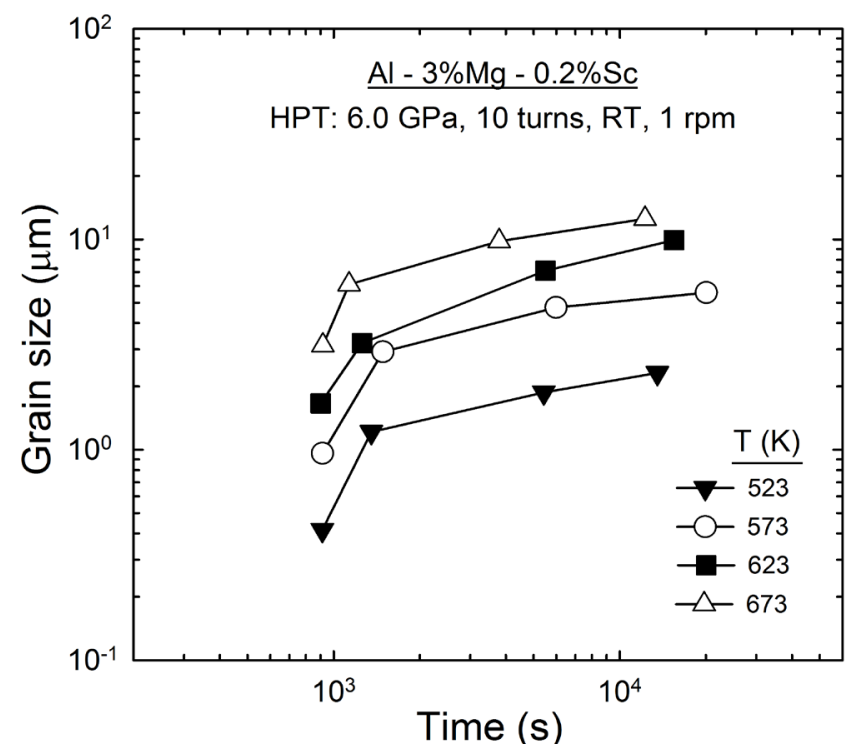

Fig. 7. Evolution of the spatial grain size, $d$, with the total heating time of the Al-3Mg-0.2Sc specimens measured at the gauge section of work-pieces tested at temperatures from 523 to $673 \mathrm{~K}$ after 10 turns of HPT processing.
623 and $673 \mathrm{~K}$ display a more significant grain growth after tensile testing, particularly in the case of the sample pulled to failure at $673 \mathrm{~K}$ which depicted spatial grain sizes higher than $\sim 10 \mu \mathrm{m}$ after total heating times of $>4 \times 10^{3} \mathrm{~s}$.

\section{Discussion}

The results depicted in Fig. 2 reveal that after 10 turns of HPT processing the microhardness distribution in the $\mathrm{Al}-3 \mathrm{Mg}$ $0.2 \mathrm{Sc}$ disc is inhomogeneous such that the central region of the sample displays low hardness values. This hardness distribution is designated hardening without recovery [28] and it is typical for materials which have low stacking fault energies and accordingly low recovery rates. Even though the Vickers microhardness is not uniform along the entire disc surface for $\mathrm{r}>\sim 1.5 \mathrm{~mm}$ the hardness values are mostly within the range from $\sim 190-210 \mathrm{Hv}$ and it is reasonable to consider that the gauge sections of the tensile specimens machined from the HPT disc have a fairly homogeneous hardness distribution.

In order to achieve superplasticity in metals the grain sizes must be typically smaller than $\sim 10 \mu \mathrm{m}$ and the testing temperature must be higher than one-half of the absolute melting temperature of the material [29]. In the present investigation both requirements were fulfilled for the Al-3Mg- $0.2 \mathrm{Sc}$ specimens processed by 10 turns of high-pressure torsion and elongations to failure $>400 \%$ were achieved at testing temperatures from 523 to $673 \mathrm{~K}$, especially at $573 \mathrm{~K}$ where an elongation of $800 \%$ was attained at $\dot{\varepsilon}=1.4 \times 10^{-2} \mathrm{~s}^{-1}$. Nevertheless, it is verified that for $\mathrm{T} \geq 623 \mathrm{~K}$ the values of the elongation to failure in the $\mathrm{Al}-3 \mathrm{Mg}-0.2 \mathrm{Sc}$ specimens diminished regardless of the initial strain rate. The reason for the decrease in the ductility of this Al-Mg-Sc alloy processed by HPT may arise from the more significant grain growth at these testing conditions because GBS may lead to the opening of cavities and cracks and thus promote premature failure in coarse-grained materials during deformation [30]. By inspection of Fig. 7, it is verified that average grain sizes $>10 \mu \mathrm{m}$ are found in the gauge section of the specimens after tensile testing at $T \geq 623$ $\mathrm{K}$ indicating that considerable grain growth occurred at these temperatures and that GBS was deleterious for the ductility of the $\mathrm{Al}-3 \mathrm{Mg}-0.2 \mathrm{Sc}$ specimens at these testing conditions.

A theoretical model was developed to predict a steady-state strain rate, $\dot{\varepsilon}$, during superplastic flow based on GBS accommodated by intragranular slip, as depicted in the following relationship [6]

$$
\dot{\varepsilon}=\frac{A D_{g b} G b}{k T}\left(\frac{b}{d}\right)^{2}\left(\frac{\sigma}{G}\right)^{2}
$$

where $A$ is a dimensionless constant, $D_{g b}$ is the coefficient for grain boundary diffusion, $G$ is the shear stress modulus, b is the Burgers vector, $\mathrm{k}$ is the Boltzmann's constant, $\mathrm{d}$ is the spatial grain size and sThe approximate value of the activation energy for superplastic flow was calculated based on Eq. (1), the temperature and grain size compensated strain rate, $\left(\dot{\varepsilon} k T / D_{g b} G b\right)(d / b)^{2}$, is plotted against the normalized stress, $\sigma / G$, in Fig. 8 using data taken from the current investigation for the Al-3Mg-0.2Sc specimens which exhibited elongations 
to failure higher than $400 \%$. The experimental points were plotted considering $\sigma$ as the maximum flow stress at each testing condition, $D_{g b}=D_{o(g b)} e^{\left(-Q_{g b} / R T\right)}$ where $R$ is the gas constant, $D_{o(g b)}=1.86 \times 10^{-4} \mathrm{~m}^{2} \mathrm{~s}^{-1}, Q_{g b}=86 \mathrm{~kJ} \mathrm{~mol}^{-1}[31], b=2.86 \times 10^{-}$ ${ }^{10} \mathrm{~m}$ [31] and $G(\mathrm{MPa})=\left(3.022 \times 10^{4}\right)-16 \mathrm{~T}$ [31]. In addition, a solid line is plotted in Fig. 8 showing the theoretical prediction for superplastic flow considering Eq. (1) with $A=15$ [32]. It is apparent from Fig. 8 that the experimental points display excellent agreement with the theoretical model. It is verified that after processing by HPT the Al-3Mg-0.2Sc alloy exhibit excellent superplastic properties, especially at 523 and $573 \mathrm{~K}$ where the highest elongations were achieved and the slope of the experimental data shown in Fig. 8 is $\sim 2$ which corresponds to the stress exponent of Eq. (1).

The approximate value of the activation energy for superplastic flow was calculated based on Eq. (1) through semi-logarithmic plots of $(1 / G T)(\sigma / d)^{2}$ against $1 / T$, as shown in Fig. 9. It is verified that the calculated values for the activation energy are in the range from $\sim 98$ to $\sim 118 \mathrm{~kJ} \mathrm{~mol}^{-1}$. Although there is some scattering in the experimental points the values estimated for the activation energy in the $\mathrm{Al}-3 \mathrm{Mg}-0.2 \mathrm{Sc}$ alloy processed by HPT were similar to the values estimated after ECAP $\left(\sim 120 \mathrm{~kJ} \mathrm{~mol}^{-1}\right)[10]$ and are within the range for grain boundary diffusion in pure $\mathrm{Al}(\sim 86$ $\left.\mathrm{kJ} \mathrm{mol}^{-1}\right)$ [31] and interdiffusion in Al-Mg alloys $(\sim 130.5 \mathrm{~kJ}$ $\left.\mathrm{mol}^{-1}\right)[33]$.

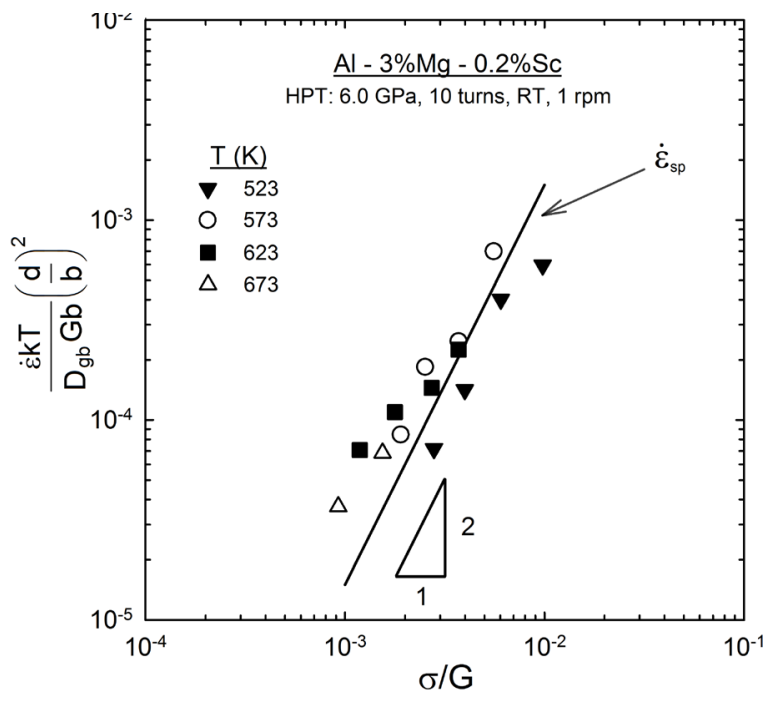

Fig. 8. Temperature and grain size compensated strain rate plotted as a function of normalized stress for the Al-3Mg- $0.2 \mathrm{Sc}$ alloy processed by HPT processing exhibiting superplastic behaviour in the current investigation. The solid line depicts the theoretical prediction for superplasticity considering Eq. (1) with $\mathrm{A}=15$ [32].

\section{Summary and conclusions}

1. The Al-3\% Mg- $0.2 \% \mathrm{Sc}$ alloy was processed by HPT through 10 turns and further subjected to tensile testing at temperatures from 523 to $673 \mathrm{~K}$.

2. After HPT processing, the Al-3Mg-0.2Sc discs depicted an inhomogeneous distribution of the Vickers microhardness along the middle-section of the samples. Hardness values within the range from $\sim 190$ to $\sim 210 \mathrm{Hv}$ were found at radial positions higher than $1.5 \mathrm{~mm}$ which correspond to the region of gauge section of the tensile specimens.

3. Excellent superplastic properties were attained in the Al-3Mg-0.2Sc alloy after HPT processing and further tensile testing. A maximum elongation of $\sim 850 \%$ was obtained at the testing temperature of $523 \mathrm{~K}$ and at the initial strain rate of $4.5 \times 10^{-3} \mathrm{~s}^{-1}$. High strain rate superplasticity was consistently observed at 573 and $623 \mathrm{~K}$, particularly at $573 \mathrm{~K}$ at strain rates of $1.4 \times 10^{-2} \mathrm{~s}^{-1}$ where elongation up to $\sim 800 \%$ were achieved.

4. Further analysis of the experimental data revealed that the stress exponent at the testing conditions displaying elongations $>400 \%$ was $\sim 2$ demonstrating good agreement with the theoretical model for grain boundary sliding. The calculated activation energies lie in the range from $\sim 98$ to $\sim 118 \mathrm{~kJ} \mathrm{~mol}^{-1}$ and are within the range for grain boundary diffusion in pure $\mathrm{Al}$ and interdiffusion in Al-Mg alloys.

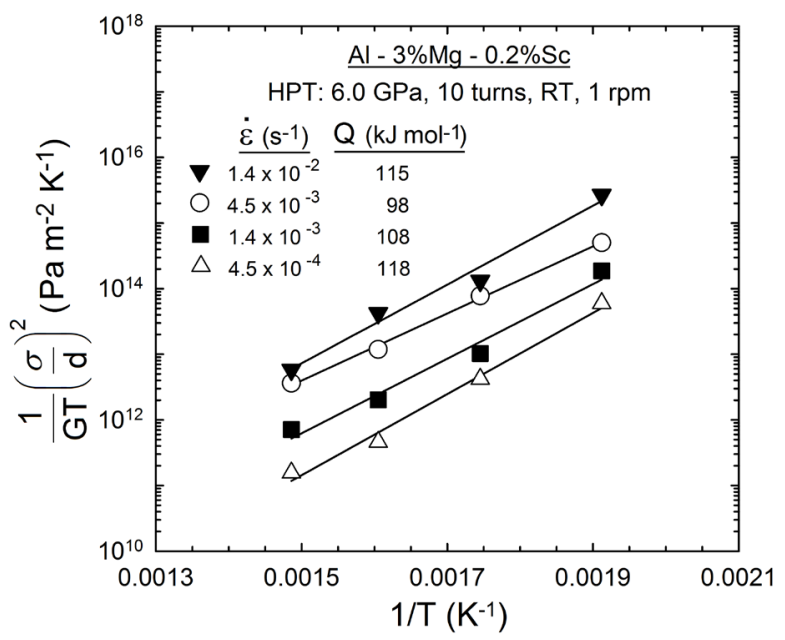

Fig. 9. Estimation of the activation energy for superplastic flow using an analysis based on Eq. (1).

Acknowledgements. The authors acknowledge support from CAPES and the European Research Council under ERC Grant Agreement No. 267464-SPDMETALS.

\section{References}

1. R.Z. Valiev, R.K. Islamgaliev, I. V. Alexandrov, Prog. Mater. Sci. 45, 103 (2000).

2. T. G. Langdon, Acta Mater. 61, 7035 (2013).

3. Y. Estrin, A. Vinogradov, Acta Mater. 61, 782 (2013).

4. R.Z. Valiev, T.G. Langdon, Prog. Mater. Sci. 51, 881 (2006).

5. A. P. Zhilyaev, T. G. Langdon, Prog. Mater. Sci. 53, 893 (2008).

6. T. G. Langdon, Acta Metall. Mater. 42, 2437 (1994).

7. R.Z. Valiev, D. A. Salimonenko, N. K. Tsenev, P. B. Berbon, T. G. Langdon, Scr. Mater. 37, 1945 (1997). 
8. M. Kawasaki, T. G. Langdon, J. Mater. Sci. 42, 1782 (2007).

9. M. Kawasaki, T. G. Langdon, J. Mater. Sci. 49, 6487 (2014).

10. S. Komura, Z. Horita, M. Furukawa, M. Nemoto, T. G. Langdon, Metall. Mater. Trans. A 32A, 707 (2001).

11. S. Komura, M. Furukawa, Z. Horita, M. Nemoto, T. G. Langdon, Mater. Sci. Eng. A 297, 111 (2001).

12. J. Gubicza, N.Q. Chinh, Z. Horita, T. G. Langdon, Mater. Sci Eng. A 387-389, 55 (2004).

13. J. Røyset, N. Ryum, Int. Mater. Rev. 50, 1 (2005).

14. F. Musin, R. Kaibyshev, Y. Motohashi, G. Itoh, Scr. Mater. 50, 511 (2004).

15. E. Avtokratova, O. Sitdikov, M. Markushev, R. Mulyukov, Mater. Sci. Eng. A 538, 386 (2012).

16. K. Dám, P. Lejček, A. Michalcová, Mater. Charact. 76, 69 (2013)

17. F. C. Liu, Z. Y. Ma, F. C. Zhang, J. Mater. Sci. Technol. 28, 1025 (2012).

18. T.G. Nieh, L.M. Hsiung, J. Wadsworth, R. Kaibyshev, Acta Mater. 46, 2789 (1998).

19. Y.L. Duan, G.F. Xu, D. Xiao, L.Q. Zhou, Y. Deng, Z. M. Yin, Mater. Sci. Eng. A 624, 124 (2015).

20. G. Sakai, Z. Horita, T. G. Langdon, Mater. Sci. Eng. A 393, 344 (2005).
21. Z. Horita, T. G. Langdon, Scripta Mater. 58, 1029 (2008).

22. Y. Harai, K. Edalati, Z. Horita, T. G. Langdon, Acta Mater. 57, 1147 (2009).

23. R. B. Figueiredo, P. R. Cetlin, T.G. Langdon, Mater. Sci. Eng. A 528, 8198 (2011).

24. P.H. R. Pereira, R. B. Figueiredo, Y. Huang, P. R. Cetlin, T. G. Langdon, Mater. Sci. Eng. A 593, 185 (2014).

25. M. Kawasaki, T. G. Langdon, Mater. Sci. Eng. A 498, 341 (2008).

26. P.H. R. Pereira, R.B. Figueiredo, P.R. Cetlin, T. G. Langdon, Mater. Sci. Eng. A 631, 201 (2015).

27. F. A. Mohamed, T.G. Langdon, Acta Metall. 23, 117 (1975).

28. M. Kawasaki, J. Mater. Sci. 49, 18 (2014).

29. T. G. Langdon, Metall. Trans. 13A, 689 (1982).

30. R. B. Figueiredo, S. Terzi, T. G. Langdon, Acta Mater 58, 5737 (2010).

31. F. A. Mohamed, T.G. Langdon, Metall. Trans 5, 2339 (1974).

32. P. Yavari, T. G. Langdon, Mater. Sci. Eng. 57, 55 (1983).

33. S. J. Rothman, N. L. Peterson, L. J. Nowicki, L. C. Robinson, Phys. Status Solidi (b) 63, K29 (1974). 